\title{
Research on Early Warning Platform of Quality Assurance System Based on BP Neural Network
}

\author{
Cuihua Sun ${ }^{1, a}$, Yong $\mathrm{Ge}^{2, \mathrm{~b}}$ and Zhengang Yao ${ }^{1, \mathrm{c}}$ \\ ${ }^{1}$ Smart Agriculture collage, Suzhou Polytechnic Institute of Agriculture, Suzhou 215008, China \\ ${ }^{2}$ Suzhou Power Supply Company, Suzhou 215004, China \\ a39938737@qq.com, b373878049@qq.com, c240725595 @qq.com
}

Keywords: BP neural network; Quality assurance system; Early warning indicators; Genetic algorithm

\begin{abstract}
This paper establish professional settings and talent supply and demand forecast and dynamic early warning mechanism, analyzes the professional evaluation index system, constructs the function module of the platform, and develops the dynamic warning platform of professional quality assurance system based on BP neural network, which is based on the professional construction quality improvement double helix as the quality assurance model, taking the specialty of higher vocational education as the research object. And Experiments show that the platform has good early warning performance.
\end{abstract}

\section{Introduction}

In September 2015, the Ministry of Education issued "the higher occupation education innovation and development action plan (2015-2018)" notice (faculty into [2015]9), proposed to build the internal and external evaluation to ensure coordination of the modern occupation education quality guarantee mechanism. Internal guarantee mechanism is the guarantee mechanism for school running quality established by school, including quality management, quality supervision and self-evaluation. Occupation education is closely related to the development of education and economy type society, professional setting, curriculum system, teaching contents, training standards must change with the changes in the industry, and mechanism of dynamic adjustment will depend on each school's own sound quality assurance system [1].

Study on BP neural network genetic algorithm has been applied to many areas of research[2], but applied to professional warning is very small, dynamic early warning platform of this study, the first time the BP neural network is applied in professional warning, improve higher vocational education quality assurance system reliability.

\section{Platform Architecture}

Function Modules of the Platform. The evaluation index system of talent training level in higher vocational colleges is divided into first level index and two level indexes [3]. Among them, the first level index contains seven modules, guiding ideology, construction of teaching staff, teaching conditions and utilization, teaching construction and reform, teaching management, teaching effect, features or innovative project. Two level indicators include the school location and School of thought, combination, structure, quality and construction, teaching facilities, teaching conditions, teaching funds, professional courses, occupation training, quality education, management team, quality control, intellectual ability, employment and social reputation[4]. According to the professional evaluation index, the function module of the platform is constructed, as shown in the Fig. 1. 


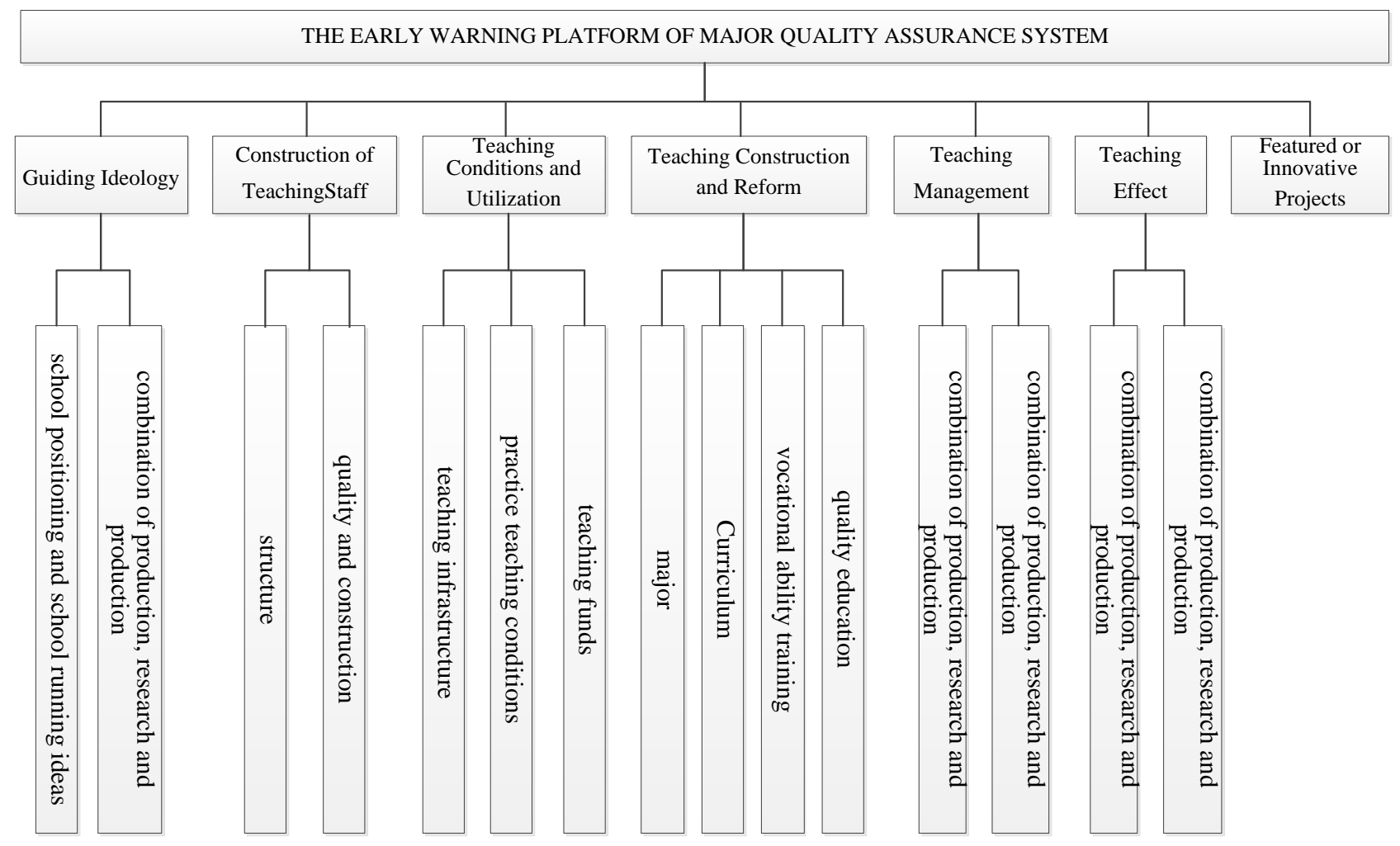

Figure 1. Finite Function module diagram of the platform

Professional Quality Improvement Double Helix. Each school, each profession must have its own definite goal of training talents; if there is a goal, there must be corresponding measures to guarantee; after that, the effect of the implementation will be checked. If the target is found to be deviation after examination, the goal will be corrected; if the target is correct, but the measures are not effective, the measures will be taken to improve it. Round and round, continuous improvement, improve quality, become a dynamic, continuous cycle improvement process [5-6]. Professional quality improvement double helixes are as shown in the Fig. 2.

The major quality improvement spiral is as follows.

Assessment: in a 3 year cycle, combined with professional leaders whose assessment.

Operation process: requirement investigation $\rightarrow$ professional planning $\rightarrow$ construction goal $\rightarrow$ construction standard $\rightarrow$ construction plan $\rightarrow$ plan implementation $\rightarrow$ self-diagnosis $\rightarrow$ diagnosis $\rightarrow$ assessment $\rightarrow$ continuous improvement $\rightarrow$ demand research.

The professional quality improvement spiral is as follows.

Assessment methods: in a 1 year cycle, combined with annual assessment.

Operation process: construction plan $\rightarrow$ plan implementation $\rightarrow$ monitoring control, $\rightarrow$ data analysis $\rightarrow$ release early warning $\rightarrow$ adjustment improvement $\rightarrow$ construction plan. 


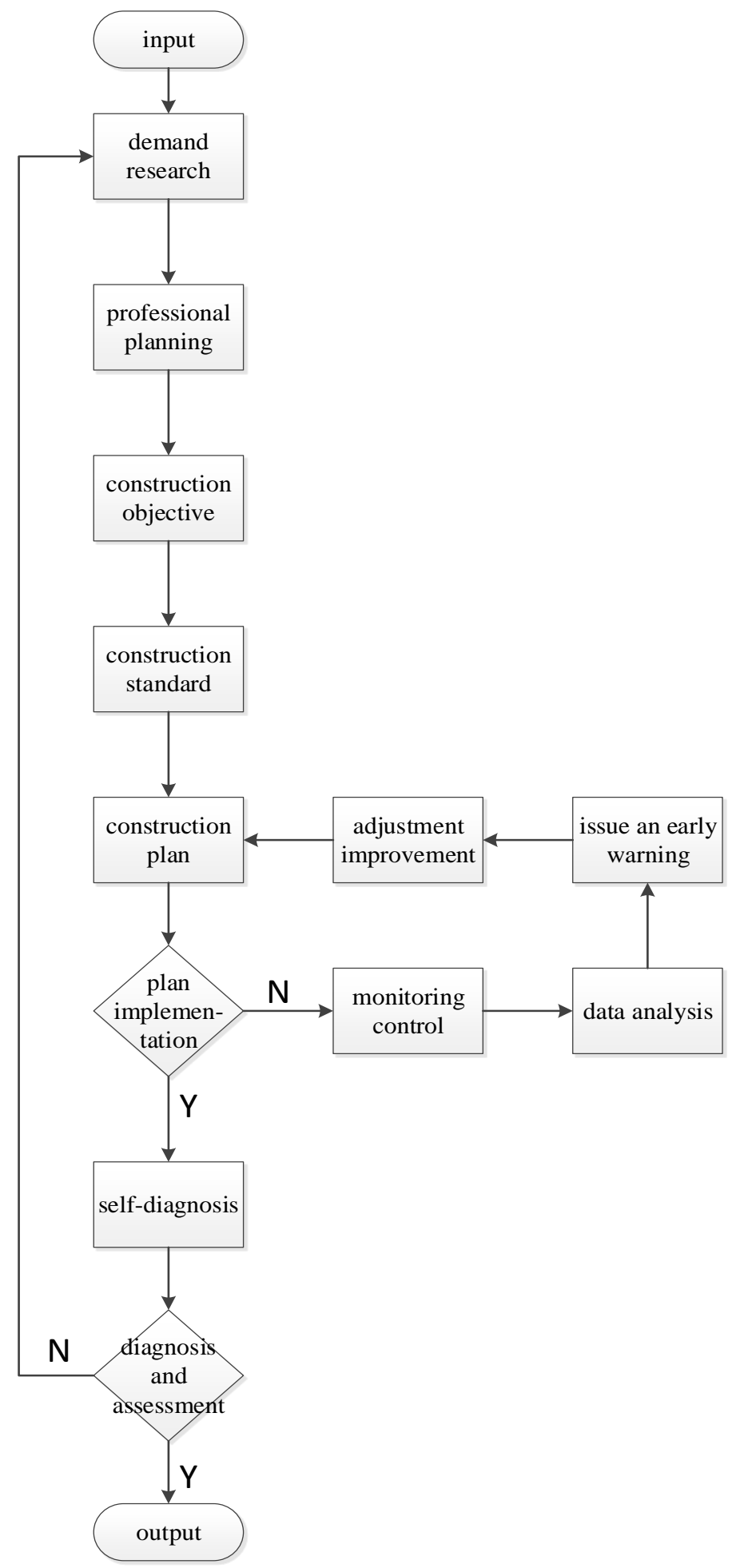

Figure 2. Finite Professional quality improvement double helixes

\section{The Key Technology}

BP neural network is a highly parallel nonlinear system is composed of a large number of processing elements are simple structure, to deal with the nonlinear problem is known, is widely used in the company's financial early warning[7], early warning of natural disasters, safety warning etc..

The main steps of BP algorithm are as follows. 
Set the input vector to $X_{1}, X_{2}, X_{3} \ldots X_{n}$; the corresponding expected output vectors are $Y_{1}, Y_{2}$, $\mathrm{Y}_{3} \ldots \mathrm{Y}_{\mathrm{m}}, \mathrm{W}_{\mathrm{ij}}$ and $\mathrm{W}_{\mathrm{jk}}$ are the connection weights between the input layer and the hidden layer, and the connection weights between the hidden layer and the output layer[8-9]. The number of input nodes is $\mathrm{n}$, and the output node is $\mathrm{m}$.

Initialization. For connection weights $\mathrm{W}_{\mathrm{ij}}, \mathrm{W}_{\mathrm{jk}}$ and threshold, $\mathrm{a}$ and $\mathrm{b}$ give the random values of $[-1,+1]$ intervals.

Calculate Hidden Layer Output. According to the input vector $\mathrm{X}$, the connection weight $\mathrm{W}_{\mathrm{ij}}$, of the input layer to the hidden layer and the threshold value of the hidden layer a are calculated, and the output of the hidden layer $\mathrm{H}$ is calculated (Eq. 1).

$$
H_{j}=\int\left(\sum_{i=1}^{n} W_{i j} X_{i}-a_{j}\right) j=1,2,3 \ldots l
$$

Calculate Output Layer Output. According to the hidden layer output $\mathrm{H}$, the connection weight $\mathrm{W}_{\mathrm{jk}}$ and the threshold $\mathrm{b}$, calculates the BP neural network prediction output $\mathrm{C}$.

Error Calculation. According to the expected input $\mathrm{Y}$ and the network prediction output $\mathrm{C}$, the network prediction error $\mathrm{E}$ is calculated (Eq. 2).

$e_{k}=Y_{k}-C_{k}, k=1,2,3 \ldots m$

Weight Updating. Update the network connection weight $\mathrm{W}_{\mathrm{ij}}, \mathrm{W}_{\mathrm{jk}}$ according to network error $\mathrm{E}$.

Threshold Update. Update the network node threshold a, B according to the network prediction error e.

\section{Simulation Experiment}

According to the basic principle of BP neural network algorithm described above, the author used the MATLAB program to establish the network model using MATLAB neural network toolbox, dynamic prediction research for professional network model is established.

This paper adopts 3 layer BP neural network, the input node number is 14, the output node number is 6 , the number of hidden layer nodes is 36 and the transfer function of hidden layer for $\mathrm{S}$ type "Tansig" function, the output layer function is $\mathrm{S}$ function "logsig" training algorithm using "Levenberg Marquart" algorithm, the maximum number of training was 1500. The training target error is 0.01 , the learning rate is 0.05 , and the momentum factor is 0.9 .

Using the initial weights and thresholds of BP neural network, it can be seen from Figure 2 that after 16 generations of genetic evolution, the best initial weights and thresholds have been obtained. Using standard BP neural network to carry out professional dynamic warning test directly, 21 of the 17 samples were correctly warned, and the correct rate of early warning reached $80.95 \%$. The experiment shows that the dynamic pre index system designed in this paper is reasonable and the dynamic alert based on BP neural network model is feasible.

\section{Conclusions}

Professional quality assurance system dynamic early warning platform, using BP neural network algorithm, Through analyzing the work state of the data on their own talent cultivation, can more clearly grasp the current situation of the development of the school and the future trend of development, higher vocational colleges to realize self-monitoring for professional quality and self-assessment, timely detection of problems, achieve scientific decision-making, macro-control, is conducive to strengthening the connotation construction, quality model, cultivating innovative talents the construction of all-round multi angle assurance system.

\section{Acknowledgements}

This work was sponsored by Qing Lan Project, supported by the education "13th Five-Year" Planning issues of Jiangsu province (B-b/2016/03/41), the modern educational technology research project of Jiangsu province (2017-R-58821), and depth integration training platform of production 
and education of Jiangsu Province on 2016 (The depth integration training platform of intelligent digital plant factory production of production and education).

\section{References}

[1] Information on http://www.moe.edu.cn/s78/A07/zcs_ztzl/ztzl_zcs1518

[2] C Ren, N An, J Wang, L Li, B Hu, D Shang. Optimal parameters selection for BP neural network based on particle swarm optimization: A case study of wind speed forecasting. Knowledge-Based Systems, Vol. 56, pp: 226-239, 2014.

[3] F.L. Zeng: Fujian Compute, Vol. 43 (2016) No.2, p.67 (In Chinese).

[4] F. H. Fang, S. Y. Pang and C. Q. Wang: Vocational Technical Education, Vol. 36 (2015) No.5, p.59 (In Chinese).

[5] L. Zhang, W. W. Ma and Y. J. Cao: journal of Anshan University, Vol. 18 (2016) No.4, p.45 (In Chinese).

[6] Z. Q. Zhao: Journal of Southwest University, Vol. 40 (2014) No.4, p.64 (In Chinese).

[7] L.F. Sun, J.B. Zhou, W.J. Lin, Z.L. He and F. Xu: Journal of Intelligence, Vol. 33 (2014) No.11, p.18 (In Chinese).

[8] $\mathrm{F} \mathrm{Yu}, \mathrm{X} \mathrm{Xu}$. A short-term load forecasting model of natural gas based on optimized genetic algorithm and improved BP neural network. Applied Energy, vol. 134, pp: 102-113, 2014.

[9] Y Zhang, X Gao, S Katayama. Weld appearance prediction with BP neural network improved by genetic algorithm during disk laser welding. Journal of Manufacturing Systems, vol. 34, pp 53-59, 2015. 